\title{
Sustainable energy management of solar greenhouses using open weather data on MACQU platform
}

\author{
$\mathrm{Li} \mathrm{Li}^{1 *}$, Jieyu Li ${ }^{1}$, Haihua Wang ${ }^{2}$, Ts. Georgieva ${ }^{3}$, K. P. Ferentinos ${ }^{4}$, K. G. Arvanitis ${ }^{5}$, N. A. Sigrimis ${ }^{5,6}$ \\ (1. Key Laboratory on Modern Precision Agriculture System Integration Research of Ministry of Education, China Agricultural University, \\ Beijing 100083, China; 2. Key Laboratory of Agricultural Information Acquisition Technology of Ministry of Agriculture, China \\ Agricultural University, Beijing 100083, China; 3. Department of Automatics and Mechatronics, University of Ruse, Ruse 7017, Bulgaria; \\ 4. Hellenic Agricultural Organization "Demeter”, Institute of Soil \& Water Resources, Dept. of Agricultural Engineering, 61 Dimokratias \\ Av., 13561, Athens, Greece \& Research Advisor at Geomations SA, spinoff of Agricultural University of Athens; 5. Department of Natural \\ Resources Management \& Agricultural Engineering, Agricultural University of Athens, Athens 11855, Greece; \\ 6. Director R\&D Department, Geosmart IKE, spinout of Geomations of AUA, Nafplio 21100, Greece)
}

\begin{abstract}
Precision energy management is very important for sustainability development of solar greenhouses, since huge energy demand for agricultural production both in quantity and quality. A proactive energy management, according to the optimal energy utilization in a look-ahead period with weather prediction, is presented and tested in this research. A multi-input-multi-output linear model of the energy balance of solar greenhouses based on on-line identification system can simulate greenhouse behavior and allow for predictive control. The good time allocation of available solar energy can be achieved by intelligent use of controls, such as store/retrieve fans and ventilation windows, i.e. solar energy to warm up the air or to be stored in the storage elements (wall, soil, etc.) or to be exhausted to outside. The proactive energy management can select an optimal trajectory of air temperature for the forecasted weather period to minimize plants' thermal 'cost' defined by an 'expert' in terms of set-points for the specific crop. The selection of temperature trajectory is formulated as a generalized traveling salesman problem (GTSP) with precedence constraints and is solved by a genetic algorithm (GA) in this research. The simulation study showed good potential for energy saving and timely allocation to prevent excessive crop stress. The active control elements in addition to predefining and applying, within energy constraints, optimal climate in the greenhouse, it also reduces the energy deficit, i.e. the working hours of the 'heater' in the sustained freezing weather, as well as the ventilation hours, that is, more energy harvest in the warm days. This intelligent solar greenhouse management system is being migrated to the web for serving a 'customer base' in the Internet Plus era. The capacity, of the concrete ground CAUA system (CAUA is an abbreviations from both China Agricultural University and Agricultural University of Athens), to implement web 'updates' of criteria, open weather data and models, on which control actions are based, is what makes use of Cloud Data for closing the loop of an effective Internet of Things (IoT) system, based on MACQU (MAnagement and Control for QUality) technological platform.
\end{abstract}

Keywords: solar greenhouse, precision energy management, energy-saving, open weather data, traveling salesman optimization

DOI: $10.25165 /$ j.ijabe.20181101.2713

Citation: Li L, Li J Y, Wang H H, Georgieva Ts, Ferentinos K P, Arvanitis K G, et al. Sustainable energy management of solar greenhouses using open weather data on MACQU platform. Int J Agric \& Biol Eng, 2018; 11(1): 74-82.

\section{Introduction}

Worldwide competition in greenhouses and, in general, agricultural production, together with an improved energy footprint

Received date: 2016-07-13 Accepted date: 2017-03-17

Biographies: Jieyu Li, Master candidate, research interests: intelligent control systems, Email: leejieyu@126.com; Haihua Wang, Associate Professor, research interests: smart agriculture systems, Email: whaihua@cau.edu.cn; Ts. Georgieva, Associate Professor, Dept Head, research interests: precision agriculture and intelligent control systems, Email: cgeorgieva@uni-ruse.bg; K.P. Ferentinos, $\mathrm{PhD}$, research interests: artificial intelligence and ICT in agriculture, controlled environment agriculture, hydroponics, Email: kpf3@cornell.edu; K. G. Arvanitis, Professor, research interests: control systems, wireless communications, precision agriculture; N. A. Sigrimis, Professor, research interests: automation systems, precision agriculture, web intelligence, smart IOT, Email: n.sigrimis@geomations.com.

*Corresponding author: Li Li, Associate Professor, research interests: smart agriculture system. Key Laboratory on Modern Precision Agriculture System Integration Research of Ministry of Education, China Agricultural University, Beijing 100083, China. Email: lily@cau.edu.cn. mandate, has brought about the problem to a higher level of complex sustainability issues and the need for a more holistic approach on the energy management aspects. However, reactive control strategies, updating operational decisions based only on the current weather condition, limits the exploitation of the long-term disturbance trends and the using effectively storage components ${ }^{[1]}$, which leads at most to short horizon predictive control scheme ${ }^{[2-6]}$. A wealth of research effort is being focused today on providing longer than instant time-horizon control strategies for energy saving and high productivity, which can average some of the parameters of interest in greenhouse cultivation (e.g. temperature integration ${ }^{[7,8]}$ ) and take preemptory action against the potential emergencies.

Some researches, based on the estimation of energy consumption, have obtained optimal operation of heating systems in a more energy-efficient way ${ }^{[4-6]}$. However, they have not taken full advantages of the storage components of the solar greenhouses, such as the wall or the soil. The optimal operations of energy storage systems in energy management of smart buildings based on 
model predictive control for longer planning time period have been widely studied as a promising solution to solve the natural mismatch between energy generation and users' demand ${ }^{[1,9,10]}$. Similarly, this pro-activeness is introduced to energy management of solar greenhouses by integrating it with the demand of the plants and the utilization of storage components for better time-allocation of energy based on the thermal model of the solar greenhouse and weather prediction. Furthermore, the crops' yield models are necessary in some greenhouse management systems and greenhouse design ${ }^{[11,12]}$, but the plants' response referenced cost function set in this research overcomes the lack of explicit yield functions for many vegetable plants and is parametric so the 'plant expert' could easily adjust for variety sensitivity and temporal crop market value. In the future, open data and information aggregates on the web for a specific crop may become the source for implicit modeling, enough for steering the energy management processes. Studies on solar greenhouses have been found in China ${ }^{[13-17]}$ in an effort to improve the design for better microclimate in winters and further structural improving for more demanding varieties or cultivation methods, i.e. soilless. Figure 1 shows an outer and an inner view of a solar greenhouse in China.

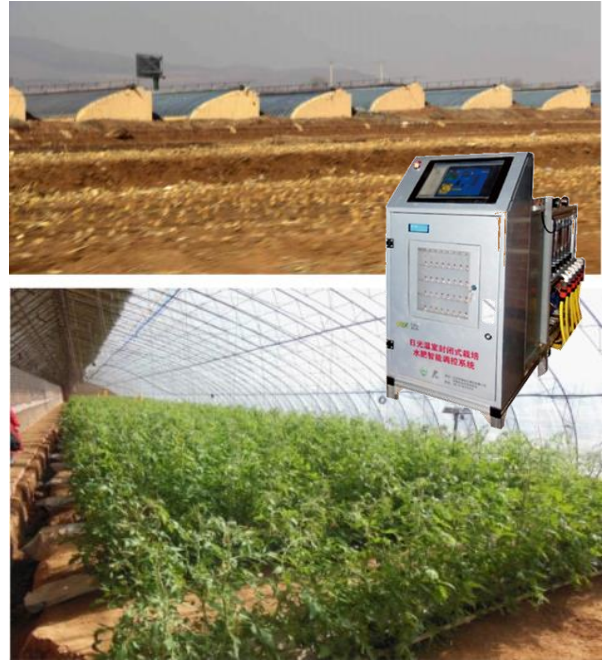

Figure 1 Pictures of modernizing the traditional solar greenhouses

Some previous researches we have done on a novel energy management method can be found in paper ${ }^{[18]}$. The system is composed of three modules: 1) identification module to update the estimated parameters, providing system properties to the predictive control; 2) the proactive energy management finds the optimal temperature trajectory for a planning period according to the weather forecast; 3) for tracking the selected trajectory in next timeslot, the controller computes and applies the controls on the simulation and the physical system of the solar greenhouse, coming up with the new sample for 1) and 2). Furthermore, this work will be transformed to a cloud based web service as a tool for making best use of forecasted services, as shown in Figure 2. This system is embedded in Management and Control for Quality (MACQU, $\mathrm{http}: / / \mathrm{www}$. geomations.com) and be on testing in the CAUA system $^{[31]}$. This system is used as an automaton local computer integrated management and intelligent control ${ }^{[19]}$ system for implementing the 'knowledge based decisions'. Knowledge (such as the crops specific nutrition requirements or the temperature response of crops) constitutes the important aspects of precision horticulture ${ }^{[20,21]}$, which upgrade the system more advanced in knowledge economy to promote to 'smart agriculture'.

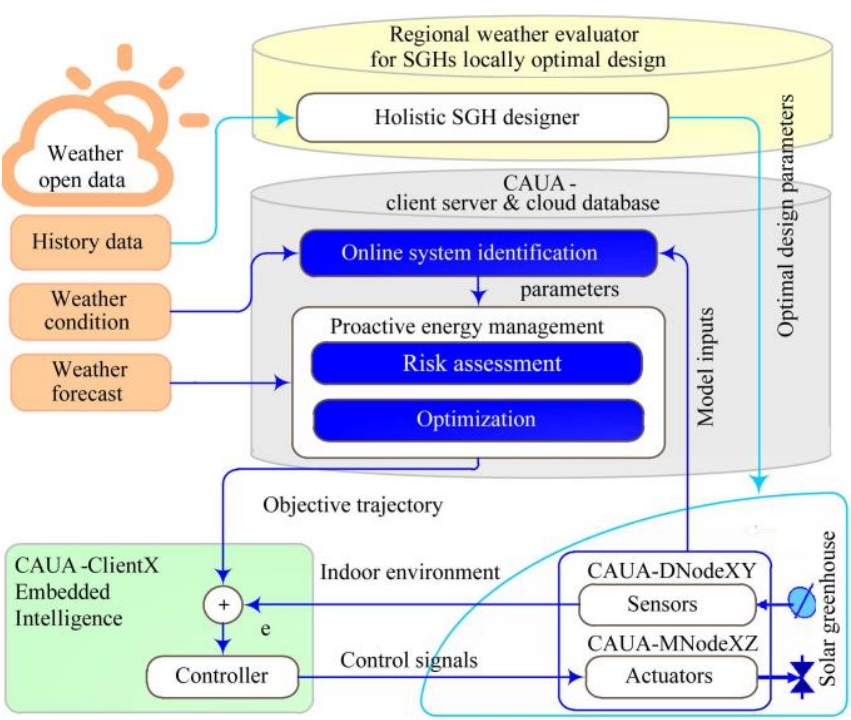

Figure 2 CAUA system with Proactive Energy Management as web services

In this research, the system is advanced by formulating the selection of set-points as a generalized traveling salesman problem (GTSP) with precedence constraints. The GTSP has been widely studied, since it can be the model for many practical problems in industries such as flowshop scheduling and toolpath planning ${ }^{[22-24]}$. The optimization issue can be dealed with a genetic algorithm (GA) combined with some powerful algorithms for local searching ${ }^{[25-27]}$.

In this simulation study, we present the pro-active energy management concept using a determined weather forecast. The management strategies were tested under different selected weather conditions, to verify its practicality and advantages. It is yet in another real application published by $\mathrm{Li}$ et al. ${ }^{[31]}$ where the system is advanced to sustainable construct and operational design, under exclusive solar energy dependence, by implementing forth-weather-based risk management, accounting local weather extremes probabilities. The basic proving steps (shown in this paper) are the same in terms of the basic pro-active concepts but the energy management processes are very different (as shown in the difference of the studied cases figures). The second paper ${ }^{[31]}$ is driven by optimal utilization of the added safety energy feature concept (SE is a specially designed small high density solar energy source) as assurance against less probable but extreme weather. It also serves as a supplement to the primary heat source (wall or soil), when weather probabilities allow, within pre-set acceptable risk figure.

\section{Materials and methods}

\subsection{Model development and analysis}

The energy and mass balance of solar greenhouses (SGHs) is analyzed in order to examine the methods of keeping indoor air temperature acceptable in cold winters, by maximizing the energy harvest/loss ratio. A model for predictive climatic management is set accordingly to maximize the temperature effectiveness on production value with a better scheduling for timely allocation of present energy reserves in the energy storage facilities of the greenhouse. More details can be found in the previous work ${ }^{[18]}$.

As for the energy balance, instantly and in few days, energy harvest rate from solar radiation $\left(Q_{\text {in }}\right)$ equals to the sum of the energy loss $\left(Q_{\text {out }}\right)$ and the energy stored rates $\left(Q_{\text {stor }}\right)$ (positive or negative):

$$
Q_{\text {in }}=Q_{\text {out }}+Q_{\text {stor }}
$$


But in long horizon, the average energy stored in the conventional heat storage structure (i.e. wall, soil, plants and air with structural elements that have some heat capacity) and the energy retrieved from it sum to zero, given that $Q_{\text {stor }}$ is a temporal in/out process that has a stable averaged value:

$$
\int Q_{\text {in }} \mathrm{d} t=\int Q_{\text {out }} \mathrm{d} t
$$

For the sake of analysis, $K_{\mathrm{gh}}$ and $A_{\mathrm{gh}}$ are introduced as relatively the average heat transfer coefficient and the average lossy area of the whole solar greenhouse on time period. Equation (2) can be modified as following:

$$
\int\left(a A^{\prime} I_{\text {rad }}\right) \mathrm{d} t=K_{\text {gh }} A_{\text {gh }} \int\left(T_{\mathrm{i}}-T_{\mathrm{o}}\right) \mathrm{d} t
$$

where, $T_{\mathrm{i}}$ and $T_{\mathrm{o}}$ are the temperature of indoor air and outdoor air respectively; $I_{\mathrm{rad}}$ is the incident solar energy; $a$ is the overall transmissivity of the solar greenhouse construction to intercepted solar radiation relating to the apparent reflectance of the covering material; and $A^{\prime}$ is the irradiated area of the greenhouse, varying along days and seasons because of the changing azimuth and horizon angle of the sun. Therefore:

$$
\int\left(T_{\mathrm{i}}-T_{\mathrm{o}}\right) \mathrm{d} t=\frac{\int\left(a A^{\prime} I_{\mathrm{rad}}\right) \mathrm{d} t}{K_{\mathrm{gh}} A_{\mathrm{gh}}}=\frac{E_{\text {in }}}{P_{\text {out }}}
$$

where, the product of $K_{\mathrm{gh}}$ and $A_{\mathrm{gh}}$ can be considered as an energy loss factor $\left(P_{\text {out }}\right), \mathrm{J} /{ }^{\circ} \mathrm{C} ; E_{\text {in }}$ is the integral of energy harvest for a time period, $\mathrm{J}$.

Obviously, in order to keep $T_{\mathrm{i}}$ in cold period, the $E_{\text {in }} / P_{\text {out }}$ ratio should be maximized. In particular, $E_{\text {in }}$ can be maximized by better design of the shape factors according to the sun azimuth. $P_{\text {out }}$ can be reduced by improving the construction of the solar greenhouses, i.e. installing thermal insulation material in most effective heat loss routes, and optimal operation of ventilation windows and night curtain. Figure 3 illustrates some solar greenhouses with different constructure design and management methods, and their performance in winters.

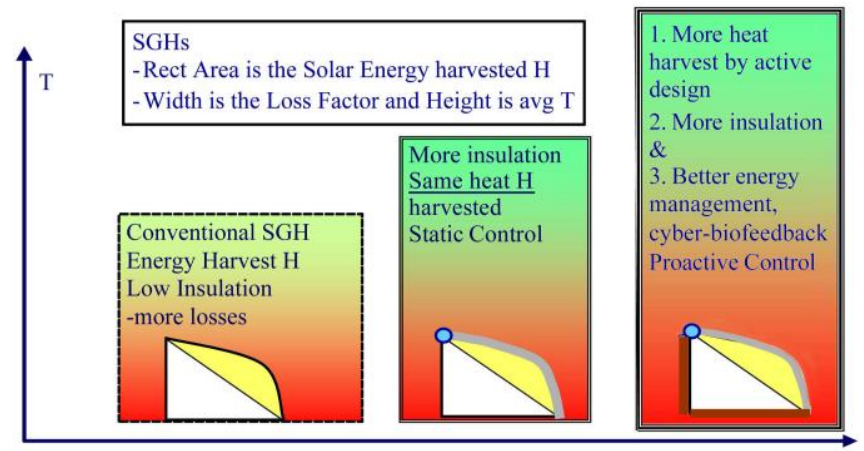

Figure 3 Solar greenhouses gain on winter temperature with better design and management

In addition, a wiser operation of the heat storage components can lead to a better, plants' diurnal response referenced and energy balance. The energy storage or retrieval procedure will be actively changed when the heat exchange rate has been changed between the heat storage structure and the air in the greenhouse. The heat exchange rate between two objects should be described by:

$$
Q=K A \Delta T
$$

where, $K$ is the coefficient of heat transfer; $A$ is the contact area; $\Delta T$ is the difference of temperature between these two objects. The efficiency of heat exchange between the air inside and the wall on the north should be raised by black plastic tubes installed in the north wall, which could increase the contact area, and active control of the store or retrieve fans to raise the energy transfer coefficient. Under the energy exchange process controlled, surplus heat can be stockpiled in the north wall when harvested energy is more than the plants' requirement and retrieved back to warm the air in the opposite situation. Smartness refers to when $K$ is modulated by fan to allocate the energy with a final target of best plants productivity while cold stress safety is guaranteed.

In details, the energy flow in the solar greenhouse equipped with thermal insulation, the ventilation windows, the curtain, wall tubes and energy storage/retrieval fans for active wall storage, and the SE (tank, solar collector and pipes under substrate), is depicted in Figure 4.

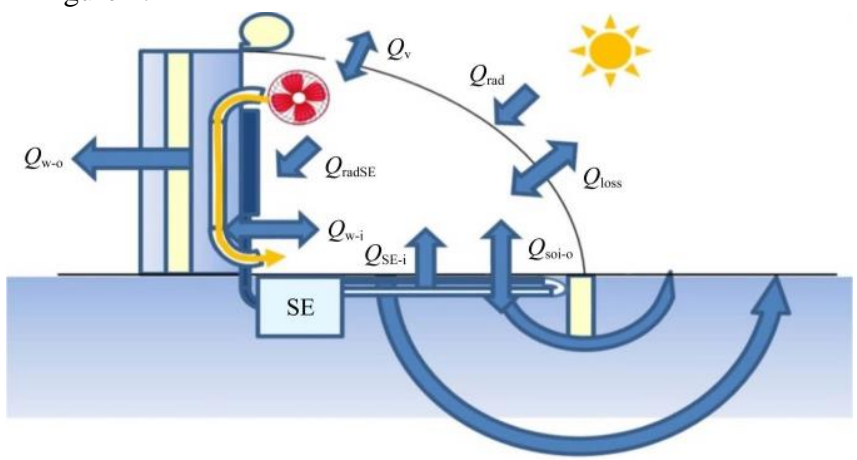

Note: $Q_{\text {rad }}$ - energy supply rate from solar radiation; $Q_{\text {radSE }}$ - energy harvest rate of solar collector (SE); $Q_{\mathrm{SE}-\mathrm{i}}$ - energy supply rate by SE; $Q_{\text {loss }}$ - the rate of heat loss through the cover; $Q_{\text {soi-i }}$ - heat transfer rate to the soil; $Q_{\mathrm{w}-\mathrm{i}}$ - heat transfer rate to the wall; $Q_{\mathrm{v}}$ - heat transfer rate due to ventilation; $Q_{\text {soi-o }}$ - heat loss rate via the soil with insulation; $Q_{\mathrm{w}-\mathrm{o}}$ - heat loss rate via the wall with insulation.

Figure 4 Energy flows and balance of the solar greenhouse

In our system, the average temperature of the air in greenhouse $\left(T_{\mathrm{i}}\right)$, of the north wall $\left(T_{\mathrm{w}}\right)$ and of the soil $\left(T_{\mathrm{soi}}\right)$ is measured and regarded as the objects being analyzed and controlled. Climatic conditions including the air temperature outside $\left(T_{\mathrm{o}}\right)$, the wind speed $\left(V_{\mathrm{wd}}\right)$ and solar radiation $\left(I_{\mathrm{rad}}\right)$ are the inputs out of control and becoming disturbance variables. Some control variables are: $u_{\mathrm{f}}$ is the control input (Pulse Width Modulation) for the store or retrieve fan; $u_{\mathrm{v}}$ is the control input for the ventilation windows representing the open state (angle); $u_{\mathrm{c}}$ is the control bit for the curtain indicating its location $\left(u_{\mathrm{c}}=0\right.$ if the curtain rises completely; $u_{\mathrm{c}}=1$ if the curtain fell completely). The curtain effects $Q_{\text {rad }}$ by blocking the sun and $Q_{\text {loss }}$ by changing the heat transfer coefficient of the cover. As a result, $u_{\mathrm{c}}$ is calculated by maximizing ( $\left.Q_{\text {rad }}, Q_{\text {loss }}\right)$.

The model for control purpose needs to be quasistatically linear, simple and complete, while the environmental factors must be considered together in a coupled system. Therefore, a Multi-Input-Multi-Output (MIMO) model with variables defined above is set for predictive control, which can be found by on-line system identification:

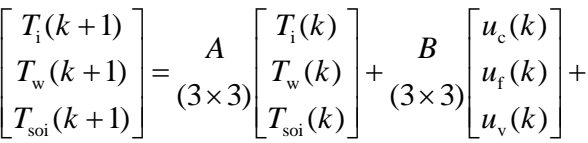

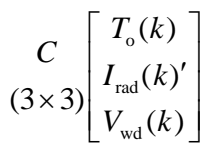

where, $I_{\mathrm{rad}}(k)^{\prime}=I_{\text {rad }}(k)\left[1-u_{\mathrm{c}}(k)\right]$ indicating the energy from solar radiation through the plastic cover, it may be zero if the curtain was totally down which could block the sun light $\left(u_{\mathrm{c}}=1\right)$. In order to identify the system as a linear model, some inputs need to be preprocessed and the parameters are estimated by recursive weighted least squares estimate (WLSE) algorithm ${ }^{[28]}$, as studied in the previous work ${ }^{[18]}$. 


\subsection{Proactive energy management}

\subsubsection{Active energy management}

To manage the time-allocation of energy at appropriated rate, active energy storage/retrieval process is achieved by managing the heat transfer rate between the inside air and the north wall while active energy discharge is realized by ventilation. An example of better time-allocation of energy is shown in Figure 5. More energy harvest is possible with the active solar greenhouse and better time-allocation of energy and high night $T_{\mathrm{i}}$, compared to passive solar greenhouse. With the energy retrieval/storage fan, the redundant energy in the air can be stored into the wall for spare, which reduces the heat stress in the meantime. This stored excess heat can be retrieved later to improve the thermal environment for the plants.

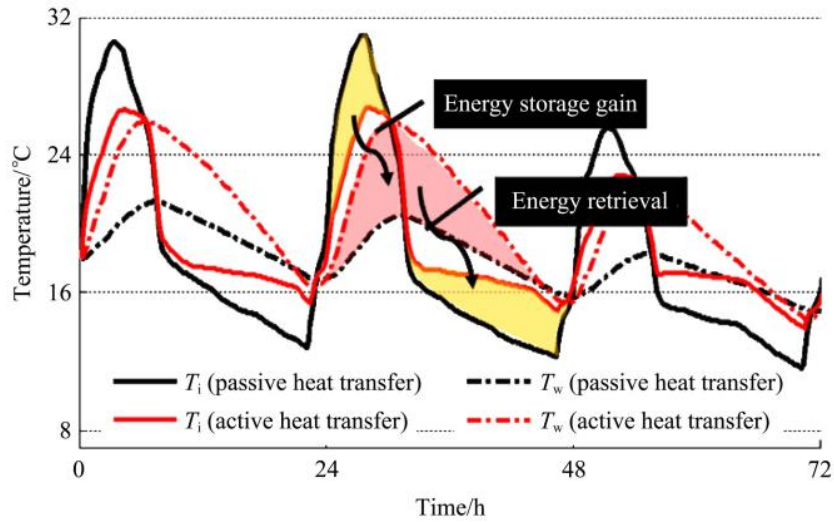

Figure 5 Better energy harvest and store/retrieve with active energy capture

A flow chart of the proactive energy management is shown in Figure 6. The control signals are calculated according to the set-points as the target values for $T_{\mathrm{i}}$ of different operations, including the set-point of energy retrieval/storage $\left(T_{\mathrm{ir}} / T_{\mathrm{is}}\right)$ and of ventilation $\left(T_{\mathrm{iv}}\right)$. Obviously, only when $T_{\mathrm{i}}>T_{\mathrm{w}}$, the heat can be transferred and stored from the air into the north wall. In this situation, the fan can be turned on for energy storage if $T_{\mathrm{i}}>T_{\text {is }}$. Similarly, if $T_{i}<T_{\mathrm{w}}$, the energy retrieval could happen. Based on the same argument, the energy is retrieved from the north wall when $T_{\mathrm{i}}<T_{\mathrm{ir}}$, to maintain $T_{\mathrm{i}}$ until $T_{w}$ decreases down to $T_{\mathrm{i}}$ by the working fan which means the energy stored in the wall is used up. In order to deal with the hot stress, when $T_{\mathrm{i}}>T_{\mathrm{iv}}$, the window is opened for ventilation.

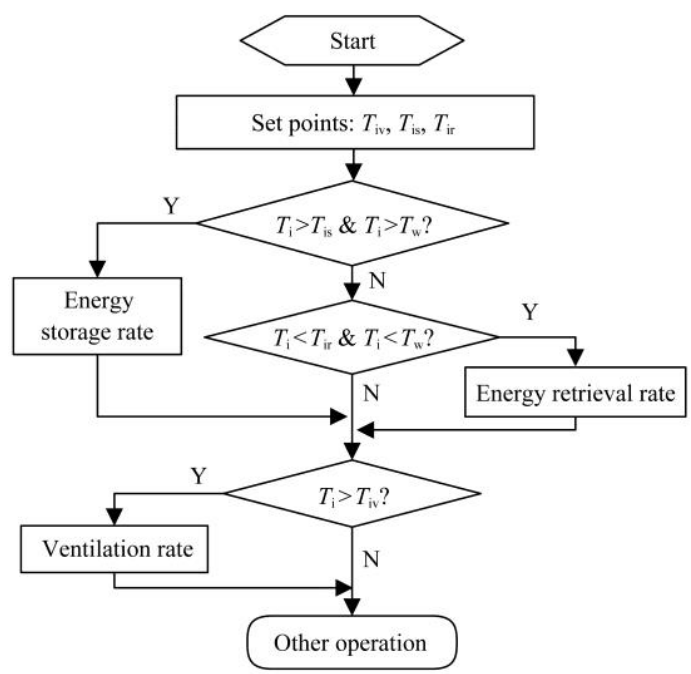

Figure 6 Flow chart of the proactive energy management and conditions-actions

\subsubsection{Cost function}

For set-points selection, a cost function is needed to evaluate the crop stress over a finite horizon. In order to define a suitable cost function, some plants sensitivity points about plants production function temperature sensitivity must be supported by the expert experience and rules. Alternatively, it will be determined by the online service from the website inspecting the solar greenhouse management. These plants sensitivity points are exemplified here and illustrated by Figure 7.

\begin{tabular}{|c|c|c|c|}
\hline $\boldsymbol{\gamma}$ & $\boldsymbol{4}$ & $\mathbf{T}$ & 4 \\
\hline $8^{\circ} \mathrm{C}$ & $16^{\circ} \mathrm{C}$ & $24^{\circ} \mathrm{C}$ & $32^{\circ} \mathrm{C}$ \\
\hline$T_{\text {cmin }}$ & $T_{\text {clow }}$ & $T_{\text {chigh }}$ & $T_{\text {cmax }}$ \\
\hline
\end{tabular}

Note: $T_{\text {cmin }}$-Big crop loss, the crop low failure temperature point; $T_{\text {clow-Cold yield }}$ loss, the crop minimum appropriate temperature point; $T_{\text {chigh }}-$ Hot yield loss, the crop maximum appropriate temperature point; $T_{\mathrm{cmax}}$-Big crop loss, the crop high failure temperature point, between $T_{\text {clow }}$ and $T_{\text {chigh }}$, no loss.

Figure 7 Segmented temperature range and the crop plants' sensitivity points

Although in this research, the temperature between $T_{\text {clow }}$ and $T_{\text {chigh }}$ seemed to have similar effect on the growth of the plants, the gap between $\left[T_{\text {clow }}, T_{\text {chigh }}\right]$ is something that also allows us a freedom for a better energy saving and may be decided according to the plants' sensitivities and crop value ${ }^{[31]}$. If the yield and value is given by the model of production and market, the Pontryagin's maximum principle can be used ${ }^{[30]}$ for self-guided decision making system rather than expert advice assessed which is preferred here. Further prosperity of the cost function can put the humidity within consideration, which will also need a complete greenhouse climate model.

In the proactive energy management, the cost value in a finite prediction horizon $N$ is optimized, but only the control signals of current timeslot is implemented, so if anything in the weather prediction is changed, the system can reevaluate and adjust in time for the next step. $N$ can be several days depending on local weather variability index. With the air temperature $\left(T_{\mathrm{iPrd}}\right)$ and the wall temperature $\left(T_{\mathrm{wPrd}}\right)$ predicted with weather forecast and parameters from system identification, the cost value to minimize can be assessed by:

$$
\begin{aligned}
J= & \sum_{n=1}^{n=N}\left\{W_{\mathrm{hl}}\left[T_{\mathrm{iPrd}}(n)-T_{\text {chigh }}\right]_{+}^{2}+W_{\mathrm{cl}}\left[T_{\text {clow }}-T_{\mathrm{iPrd}}(n)\right]_{+}^{2}+\right. \\
& \left.W_{\mathrm{TL}}\left(\left[T_{\mathrm{iPrd}}(n)-T_{\mathrm{cTL}}\right]_{+}+\alpha\right)^{-2}\right\}-W_{\mathrm{ws}} T_{\mathrm{wPrd}}(N)
\end{aligned}
$$

where, function $[\cdot]_{+}=\max (\cdot, 0)$, all the weights are non-negative variables. $\quad W_{\mathrm{hl}}$ is the weight for high temperature plant suffer loss, disease risk and heat stress when $T_{\mathrm{iPrd}}(n)>T_{\text {chigh }} \cdot W_{\mathrm{cl}}$ is the weight for low temperature plant suffer loss, disease risk and cold stress when $T_{\mathrm{iPrd}}(n)<T_{\text {clow. }} J$ dramatically rises when $T_{\mathrm{iPrd}}$ drops near $T_{\mathrm{cTL}}$ which leads to total crop loss, weighted by $W_{\mathrm{TL}}$, so it is meaningless if $J$ shows the continuous growth when $T_{\mathrm{iPrd}}(n)<T_{\mathrm{cTL}}$. $\alpha$ is a small value preventing denominator to be zero. $T_{\mathrm{wPrd}}(N)$ is the temperature of the north wall at last sample in the predictive horizon. $W_{\text {ws }}$, the weight of the north wall storage, is the energy value normalizing factor which could be inversely affected by the weather inside, the heat insulation affection and the different stages of the plant in greenhouse. Higher $W_{\text {ws }}$ speeds the system to be more conservative, showing that the values of energy stored are more important relative to the output damaging. In conclusion, the stress of crops is diminished while more spare energy is stored in the wall for the following days with the best optimum set-points ( $T_{\mathrm{br}}, T_{\mathrm{bs}}$ and $T_{\mathrm{bv}}$ ) found by minimizing $J$. A surface of cost values (after normalization) is in Figure 8. 


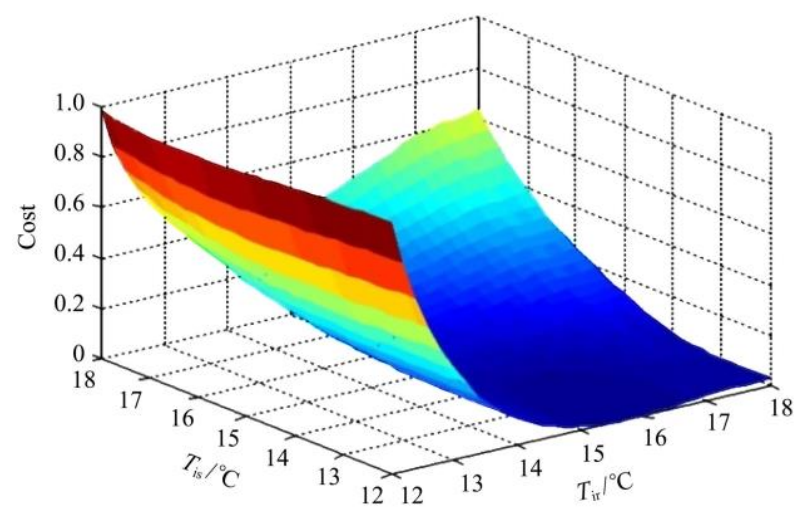

Figure 8 Normalized cost function surface for seeking optimal set-points

$J$ can be improved to be better weighted to local weather behavior as well as possible disease preferences epidemics. The different parameters lead to different selections of the set-points which may match better some plants' preference and tolerance to the temperature conditions. Some tests are conducted under the same weather condition but with different parameters (see Table 1). As shown in the comparison between Test 1 and Test 2, the larger $W_{\mathrm{hl}}$ decreases $T_{\mathrm{bv}}$, which can protect the plants sensitive to high temperature. The comparison between Tests 2 and 3 shows that if plants suffer high risk with low temperature, parameter $W_{\mathrm{TL}}$ should be larger for shooting the case near $T_{\mathrm{cTL}}$, which leads to a smaller $T_{\mathrm{br}}$. It's because that lower $T_{\mathrm{br}}$ can utilize the limited energy from the wall more slowly to maintain $T_{\mathrm{i}}$ in the suboptimal range for a longer time.

Table 1 Comparison of chosen set-points with different parameter in cost function

\begin{tabular}{cccccccccc}
\hline & \multicolumn{4}{c}{ Parameter setting } & & \multicolumn{2}{c}{ Chosen set-points } \\
\cline { 2 - 6 } \cline { 5 - 8 } Items & $T_{\mathrm{cTL}} /{ }^{\circ} \mathrm{C}$ & $W_{\mathrm{hl}}$ & $W_{\mathrm{cl}}$ & $W_{\mathrm{TL}}$ & $W_{\mathrm{ws}}$ & $T_{\mathrm{br}} /{ }^{\circ} \mathrm{C}$ & $T_{\mathrm{bs}} /{ }^{\circ} \mathrm{C}$ & $T_{\mathrm{bv}} /{ }^{\circ} \mathrm{C}$ \\
\hline Test 1 & 4 & 0.05 & 0.01 & 1 & 0.1 & 17.2 & 16 & 24.5 \\
Test 2 & 4 & 0.01 & 0.01 & 1 & 0.1 & 18 & 16 & 26 \\
Test 3 & 4 & 0.01 & 0.01 & 10 & 0.1 & 17.2 & 16 & 26 \\
\hline
\end{tabular}

2.2.3 Problem formulated as a generalized traveling salesman problem

The available energy, including the harvested energy from solar radiation and the actively stored energy, is used according to the set-points to meet the plants' thermal demand against the outside temperature. As the ratio of the available energy to the required energy is varying with the changing weather, the situation that the stored energy is far beyond the needed energy in a sunny day and hardly enough in a cloudy day can happen in two days of the planning period. Therefore, the set-point found for the whole planning period (several days) may not be a precise and the optimum solution addressing the situation in the next timeslot, especially for the fluctuated weather.

In order to solve this problem, the optimization has been improved by dividing the planning period into segments to independently find different set-points for each energy management process. The set-points are selected based on each segment respectively, called segment-variant set-points (SV), compared to the segment-invariant set-points (SI) as a constant value taking care of the whole planning period in the previous $\operatorname{work}^{[18]}$.

The selection of optimal set-points is formulated as a GTSP. The travelling salesman problem is to find the shortest possible route that visits each city exactly once and returns to the origin city, given a list of cities and the distances between each pair of cities. In a GTSP, cities are grouped into several mutually disjoint districts, and the traveling salesman has to visit one city in each district following the shortest route. As for the selection of the optimal set-points in the proactive management, the weather forecast period is divided into non-overlapping and successive time segments which can be considered as the districts. It can be done according to the sunrise indicating new energy supply available or the comparison between the required and available energy determining whether energy storage or retrieval is needed in this time segment.

Let the segment-variant set-points $\left(T_{\text {is.Sv }}, T_{\text {ir.Sv }}, T_{\text {iv.Sv }}\right)$ to be set into a vector $T_{\mathrm{sp}} . \quad T_{\mathrm{sp}}^{c, d}$ is the $c^{\text {th }}$ candidate set-points vector in the segment $d$, which can be considered as the $c^{\text {th }}$ city in the district $d$ $(c=1,2, \ldots, C ; d=1,2, \ldots, D$; where $C$ is the total number of the set-points vectors in the searching space and $D$ is the total number of segments in the planning period). $\quad T_{\mathrm{iPrd}}^{c, d}$ is the predictive temperature with the operations according to set-points $T_{\mathrm{sp}}^{c, d}$. The last sample of the predictive air temperature in the previous segment $\left(T_{\mathrm{iPrd}}^{c^{\prime}, d-1}\right)$ is needed as the initial state to predict $T_{\mathrm{iPrd}}^{c, d}$. A cost value, calculated according to $T_{\mathrm{i} P \mathrm{rd}}^{c, d}$, can be considered as one possible distance from the $c^{\text {th }}$ city in district $d-1$ to the $c^{\text {th }}$ city in district $d$. As the iteration for segments goes on, the minimum cost in the whole planning period can be achieved by minimizing the total distance traveling along districts. Therefore, the optimization of set-points is like a GTSP but with two important differences: since the segments in the planning period need to be in time order, the salesman has to visit one city (set-points) in each district (time segment) while obeying the precedence constraints among the districts without returning back to the starting point. The metaphor is depicted in Figure 9.

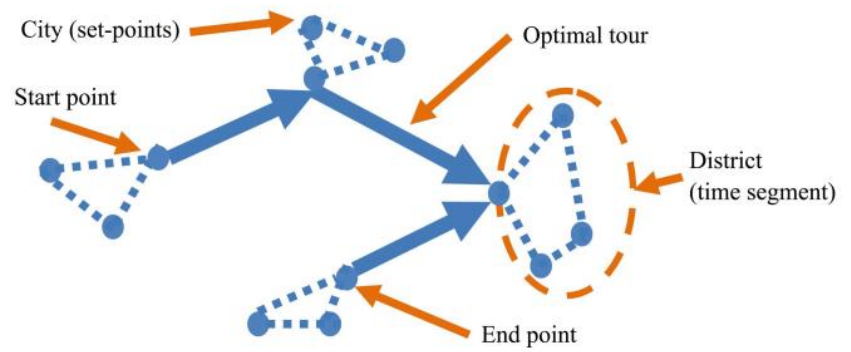

Figure 9 Instance of the GTSP

Genetic algorithms (GAs), widely used amongst modern heuristics for optimization problems, can be effective solution methods to solve this problem. The principles of GAs are well known: it begins with a population of randomly generated solutions which is picked out according to the fitness and evolved toward better solving process by mutation and cross over; the generation process will reach the termination qualification when the fittest individual is as the solution to the optimization problem. In this case, various combinations of the set-points for the weather forecast period are considered as the individuals with different chromosomes; and the fitness is negatively correlated with the cost value. Furthermore, two termination criteria, if fixed number of generations is reached or several successive iterations no longer produce better results, are combined as the terminating condition. The flowchart of the optimization problem solved by a GA is in Figure 10. 


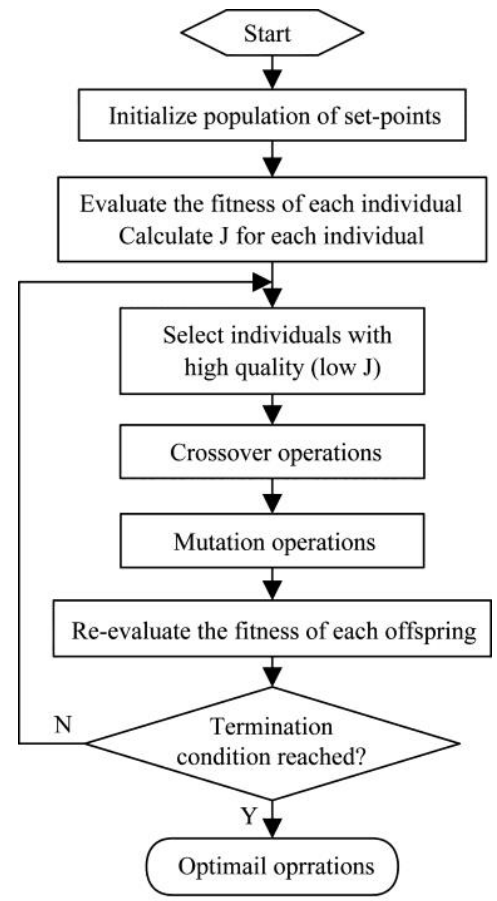

Figure 10 Flowchart of the optimization problem solved by a GA

An example of the improved performance is shown in Figure 11 with the comparison between the optimal set-points for energy retrieval $\left(T_{\mathrm{br}}\right)$ found by the two policies and the resultant predictive temperature $\left(T_{\mathrm{iPrd}}\right)$. The weather forecast indicates that the temperature and the solar radiation will experience a sudden rise in the third day.

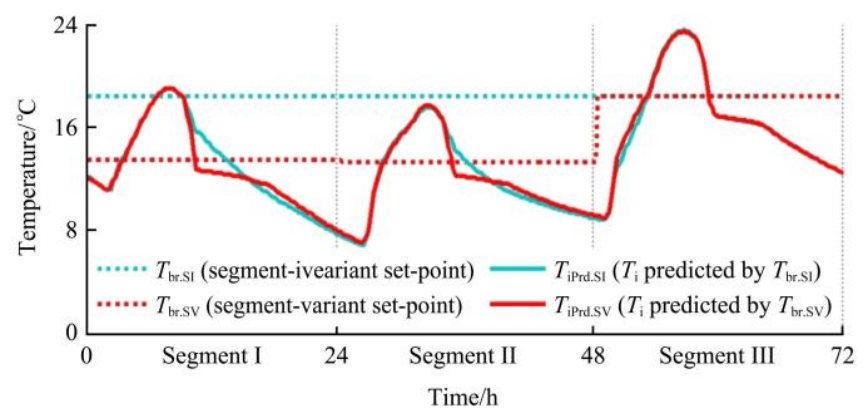

Figure 11 Predictive trajectories comparison under fluctuated weather

$T_{\text {br.sv }}$ indicates the trajectory of segment-variant set-point independently found to take care of each separated energy retrieval process, while $T_{\text {br.SI }}$ is the optimal segment-invariant set-point sustained in a constant value for the whole planning period. For the optimization of $T_{\text {br.SI }}$, the cost value of the whole period can be minimized by decreasing the set-point to take care of the shortage of stored energy in the first two segments or by increasing the set-point to use a greater amount of the redundant stored energy in the Segment III. In this case, increasing $T_{\text {br.SI }}$ is a more effective way according to the weather forecast. However, both of the solutions can be applied with the $T_{\mathrm{br} . \mathrm{Sv}}$, which reduces the predictive cost from 163.45 to 159.15 compared to the performance of $T_{\text {br.SI }}$. This indicates that $T_{\text {br.SI }}$, found as a constant value for the whole predictive period, may not be the optimal set-points of the next timeslot, especially with dramatic change of weather. Only the first segment of the trajectory is implemented by the controllers as the trajectory will be recomputed with the next data sample.

\section{Results and discussion}

\subsection{Performance of GA}

The convergence rates and performance are shown in Figure 12 by the cost values in the iteration process (negatively correlated with the fitness in the GA). The total population of a generation is 300 , and 35 inferior individuals are replaced by better ones in the equal number.

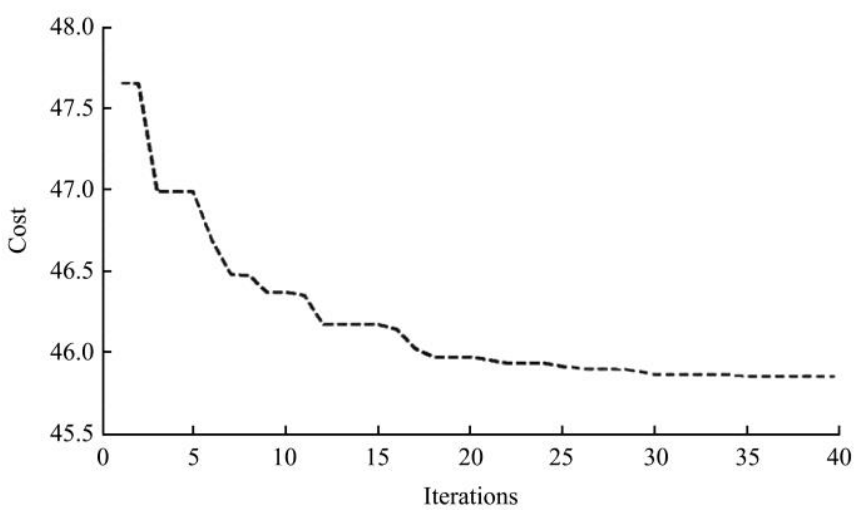

Figure 12 Performance of GA

\subsection{Performance of the controllers}

The parameters in the tests are set as follows: the $\mathrm{N}$ is the weather forecast period, which is set to be 3 days. The sampling interval is set to be $10 \mathrm{~min}$. The parameters in cost functions for the proactive energy management are: $\quad W_{\mathrm{hl}}=0.02 ; W_{\mathrm{cl}}=0.01$; $W_{\mathrm{TL}}=50 ; W_{\mathrm{ws}}=2$. Figure 13 shows the performance of the controllers.
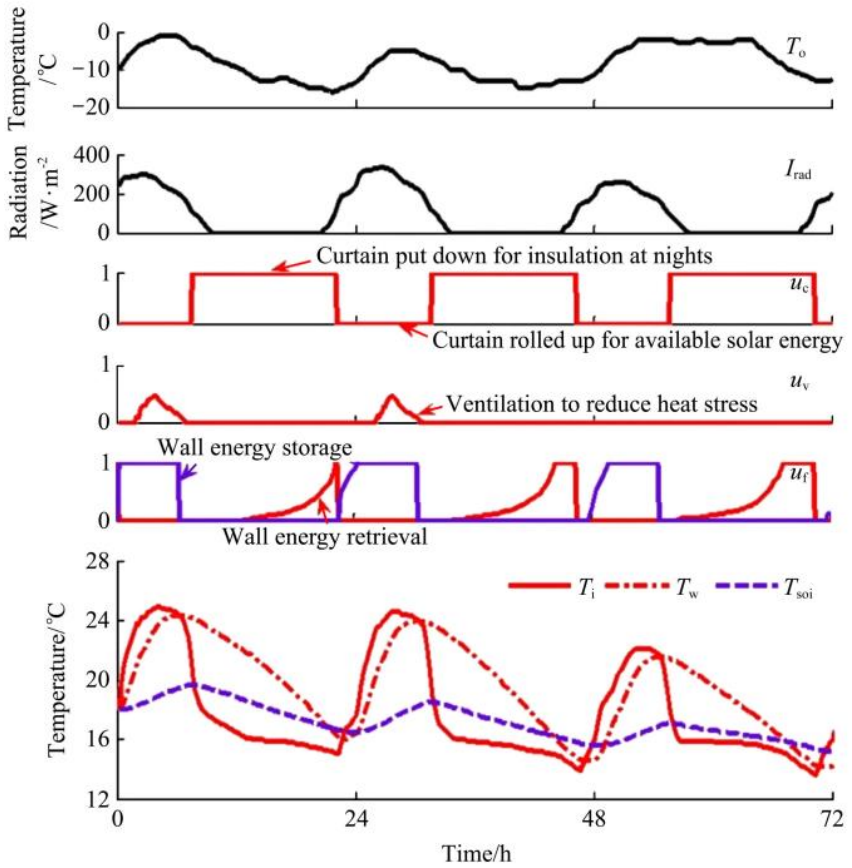

Figure 13 Performance of the control strategies

The fan controlled by the machine using the PID algorithm, which is trying to keep $T_{\mathrm{i}}$ at $T_{\mathrm{br}}$ or $T_{\mathrm{bs}}$. However, $T_{\mathrm{i}}$ cannot stay at $T_{\mathrm{bs}}$ in the processing of the energy storage, because the huge energy income from adequate solar radiation and the tiny energy exchange between the air indoor and the wall of the north; $T_{\mathrm{i}}$ declines with $T_{\mathrm{w}}$ in the heat retrieval process owning to the limited energy in the north wall.

\subsection{Simulation studies under different weather}

For testing, the needed heating time, indicating the duration 
that $T_{\mathrm{i}}$ is lower than the low failure temperature point $\left(T_{\mathrm{cmin}}\right)$, is an important factor to evaluate the performance of different energy management methods. Besides, as regards the crops' productive environment, a capability of climate quality function $g(t)$ is defined. $g(t)$, is the area $\left({ }^{\circ} \mathrm{C} \cdot \mathrm{h}\right)$, related to the essential safety energy, inclosed by the temperature curve $T_{\mathrm{i}}$ and the line of $y=T_{\text {cmin }}$, it defined in the following Equation (8):

$$
\left.g(t)=\sum_{m=1}^{m=M} \int_{t_{\text {stt }}(m)}^{t_{\text {end }}(m)}\left[T_{\mathrm{i}}(t)-T_{\mathrm{c} \text { min }}\right] \mathrm{d} t \quad\left(T_{\mathrm{i}}(t)\right)<T_{\mathrm{c} \text { min }}\right)
$$

where, $M$ is the whole number of the pieces of cycle time, which $T_{\mathrm{i}}$ should be smaller than $T_{\text {cmin }}$, also $t_{\text {stt }}(m)$ and $t_{\text {end }}(m)$ are the starting and end point of the time slice $m$ respectively. $g(t)$ as defined above should prevent damaging effects on crops productivity or the first level cold stress (below $T_{\text {cmin }}$ ).

Lots of experiments with different control policies were implemented based on some special conditions, like warm and cold weather. The different control policies are set as follows: all the experiments are conducted based on the same situation of the curtain operation according to the heat balance by the coverage; as for the ventilation and wall storage management, experiment identifiers 'P', ' $\mathrm{F}$ ', and ' $\mathrm{N}$ ' representing 'ventilation and wall storage operation with proactive energy management', 'both operated with fixed set-points' and 'inoperative ventilation and energy retrieval/storage fan' respectively. The settled set-points are: $T_{\text {is }}=T_{\text {ir }}=T_{\text {clow }}=16^{\circ} \mathrm{C}, T_{\text {ir }}=T_{\text {iv }}=T_{\text {chigh }}=24^{\circ} \mathrm{C}$.

Example the winter days (from Day-1, Day-2 to Day-3) were picked out to show for each situation how the control policies have a profound effect on the thermal condition inside the solar greenhouse. For the purpose of analysis, the optimal set-points would be replaced in this experiment every day, instead of every timeslot. The temperature data of weather and the selected set-points from the proactive energy management of $3 \mathrm{~d}$ are shown in the Table 2. Figure 14 shows the test results and Table 3 presents some detailed statistics.
Table 2 Temperature of the weather and selected set-points by proactive policy

\begin{tabular}{ccccc}
\hline \multicolumn{1}{c}{ Items } & Day-1 & Day-2 & Day-3 \\
\hline \multicolumn{2}{c}{ Average $T_{\mathrm{o}} /{ }^{\circ} \mathrm{C}$} & -5.0 & -13.0 & -20.0 \\
Maximum $I_{\text {rad }} / \mathrm{W} \cdot \mathrm{m}^{-2}$ & 350 & 350 & 260 \\
\hline \multirow{4}{*}{ Set-points $/{ }^{\circ} \mathrm{C}$} & $T_{\text {br.P }}$ & $T_{\text {br.P }}(1)=18.4$ & $T_{\text {br.P }}(2)=18.0$ & $T_{\text {br.P }}(3)=12.8$ \\
& $T_{\text {bs.P }}(1)=14.0$ & $T_{\text {bs.P }}(2)=9.0$ & $T_{\text {bs.P }}(3)=8.0$ \\
& $T_{\text {bv.P }}$ & $T_{\text {bv.P }}(1)=26.5$ & $T_{\text {bv.P }}(2)=30.0$ & $T_{\text {bv.P }}(3)=30.0$ \\
\hline
\end{tabular}

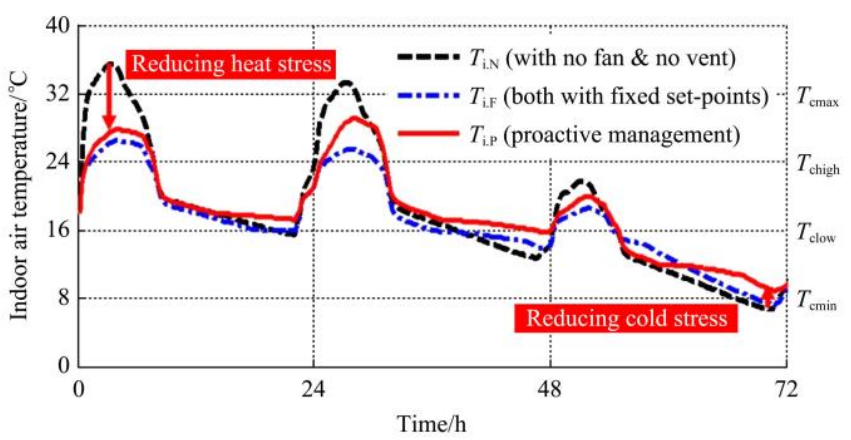

a. Indoor air temperature

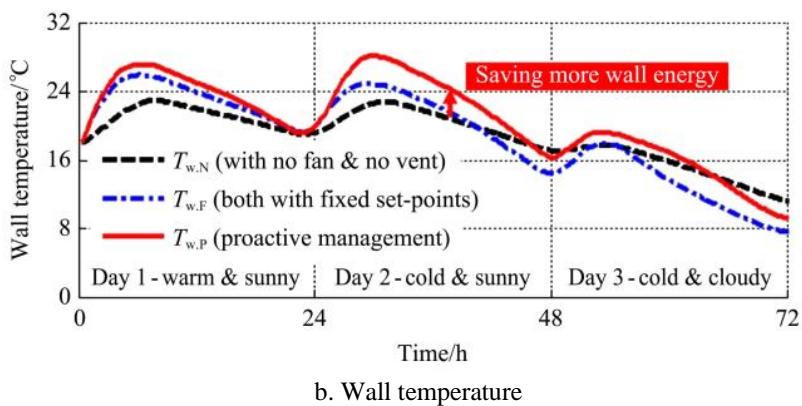

Figure 14 Simulation of air and wall with different control policies

Table 3 Summary of the simulation results

\begin{tabular}{lcccccc}
\hline \multicolumn{1}{c}{ Tests } & Highest $T_{\mathrm{i}} /{ }^{\circ} \mathrm{C}$ & Lowest $T_{\mathrm{i}} /{ }^{\circ} \mathrm{C}$ & Average $T_{\mathrm{i}} /{ }^{\circ} \mathrm{C}$ & Vent hours/h & Needed heating time/h & $g(t) /{ }^{\circ} \mathrm{C} \cdot \mathrm{h}$ \\
\hline No vent and active wall (N) & 35.47 & 6.74 & 18.28 & 0.00 & 3.03 \\
Fixed set-point policy (F) & 26.56 & 7.11 & 17.05 & 13.00 & 225.88 \\
Proactive management (P) & 29.11 & 8.87 & 18.19 & 5.50 & 1.07 & 0.00 \\
\hline
\end{tabular}

Figure 14 shows that $T_{\mathrm{i}, \mathrm{N}}$ is the worst performance owing to without ventilation and proactive heat storage on the wall. As in Table 3, the installation of ventilation windows, energy retrieval/storage fan and the tubes in the north wall can realize a better thermal surrounding inside for the plants growing, which reduces the cost value from 225.88 to 106.96 ; and the proactive energy management further improves the cost to 85.36 by the better time- distribution of the heat.

In the simulation test, Day-1 represents a warm and sunny day in winters, so the key consideration is the crop yield stress caused by high temperature. The ventilation is verified to decrease the heat stress more effectively by reducing the highest $T_{\mathrm{i}}$ in Day-1 from $35.47^{\circ} \mathrm{C}$ to around $27^{\circ} \mathrm{C}$.

There is sufficient solar radiation in Day-2, and it's important to keep more stored energy since the coming bad weather. Therefore, proactive energy management choses the $T_{\text {bv.P }}(2)$ to be 30.0 , higher than the fixed set-point $\left(T_{\mathrm{iv} . \mathrm{F}}=24^{\circ} \mathrm{C}\right)$, which leads to less energy loss from ventilation and thus more spare heat stored in the north wall indicated by the fact that $T_{\mathrm{w} . \mathrm{P}}$ is higher than $T_{\mathrm{w} . \mathrm{F}}$. The comparison of the proactive set-points in Day-1 and Day-2 shows that the proactive energy management optimizes the thermal environment while taking the potential emergencies into consideration. The proactive set-point of wall energy storage is decreased from $14^{\circ} \mathrm{C}$ in Day- 1 to $9^{\circ} \mathrm{C}$ in Day-2 to allow more energy saved in the wall; and the proactive set-point of ventilation is increased from $26.5^{\circ} \mathrm{C}$ in Day- 1 to $30^{\circ} \mathrm{C}$ in Day-2 to keep more energy inside the greenhouse for the coming cold days. Furthermore, since the proactive energy management allows no ventilation in Day-2, we can notice from the comparison between $T_{\mathrm{i} . \mathrm{P}}$ and $T_{\mathrm{i} . \mathrm{N}}$ that the hot stress can also be reduced by the wall energy storage process.

In Day-3, the weather is critical cold and obviously the solar radiation is not adequate. $T_{\mathrm{i} . \mathrm{P}}$ and $T_{\mathrm{i} . \mathrm{F}}$ compare with one another and show that the proactive energy management is more effectively by using the north wall storage, i.e. increasing the lowest temperature from $7.11^{\circ} \mathrm{C}$ to $8.87^{\circ} \mathrm{C}$. It is attributed to the more spare energy stored in Day-2 and a wiser utilization of the available energy with a lower $T_{\text {br.P }}(3)$ as $12.8^{\circ} \mathrm{C}$. Although the higher fixed set-point $\left(T_{\mathrm{ir} . \mathrm{F}}=16^{\circ} \mathrm{C}\right)$ controls the fan to retrieve the heat earlier to keep $T_{\mathrm{i} . \mathrm{F}}$ nearby to the optimal temperature at the beginning of the 
test, $T_{\mathrm{i} . \mathrm{F}}$ drops down to a lower point more quickly because the wall storage is short and limited, but $T_{\text {i.P }}$ can be insisted for a longer time on the suboptimal span.

\section{Conclusions}

An utility energy management method is developed for long term solar energy utilization. It also minimized the potential plant stress efficiently by choosing an optimal trajectory for the forecasted weather condition according to the web customer support service. It is tested currently on CAUA system (a SCADA system) to promote the energy sustainability of the Solar Greenhouses.

The simulation study shows that with analog control on ventilation and active energy storage/retrieval by a fan, the proactive energy management can gain on climate cost, and reduce the crop stress caused by high and low temperature. In an example with warm weather and sufficient solar radiation, the proactive management can set the air temperature inside the greenhouse within a best favorable range for the plants. As for an extreme cold condition, it was proved that the proactive management, compared to conventional automation, increases the minimum temperature from $6.74^{\circ} \mathrm{C}$ to $8.87^{\circ} \mathrm{C}$, which in other marginal conditions can save the whole crop. Therefore, it is an effective and economical energy management mechanism for saving energy and improving productivity with only additional active storage capacity (a small fan and wall tubing to actively store and retrieve energy from wall storage) and a small constructive investment. Furthermore, the model predictive control, optimizing the trajectory in a finite prediction horizon, can take preemptory actions against the potential emergencies, by updating control signals with every data sample which allows timely utilization of a more recent forecast for regularly optimized control pro-actions. The introduction of the generalized traveling salesman problem solved by a genetic algorithm fits the optimization problem with a more efficient method and a broader searching space, and therefore brings a better tuned instant operation and a higher tolerance to fluctuating weather.

The study is ready to transfer the control policies to a web service for managers of solar greenhouses, and also to be open for receiving other web services or open data, e.g. market value predictions or micro-scale weather forecasts. It is a realization of the real advantage of the IoT modern approaches for a web hypermarket that can provide practical benefits to farmers and consumers. Future ground works focus on improving the system for its value of sustainability, investment cost and farmer economy by introducing safety energy as a special storage to meet the energy needs under extreme non-probable weather while taking the weather-related risk into account.

\section{Acknowledgement}

This research was supported by the National Key Research and Development Program of China (2016YED0201003) and the Yunnan Academician Expert Workstation (Wang Maohua, Grant No. 2015IC16). The authors wish to thank Acad. Prof. Wang Maohua (member of CAE), the leader of the team for solar greenhouse closed cultivation system and Prof Nick Sigrimis, the cooperation supervisor of the research group, supporting the societal challenges of giving returns to People from research investments. The basic MACQU technology has been developed from a number of European and Greek-China cooperation projects and is currently supported by TEAP EU-CHINA project on developing CAUA technological platform that can have many applications in the field of modernizing the agro-food industry.

\section{Nomenclature}

\begin{tabular}{|c|c|}
\hline \multicolumn{2}{|r|}{ Disturbance variables } \\
\hline$\overline{T_{\mathrm{o}}}$ & Outdoor air temperature, ${ }^{\circ} \mathrm{C}$ \\
\hline$I_{\mathrm{rad}}$ & Solar radiation, $\mathrm{W} \cdot \mathrm{m}^{-2}$ \\
\hline$V_{\mathrm{wd}}$ & Outdoor wind speed, $\mathrm{m} \cdot \mathrm{s}^{-1}$ \\
\hline \multicolumn{2}{|r|}{ Other symbols } \\
\hline $\bar{T}$ & Temperature, ${ }^{\circ} \mathrm{C}$ \\
\hline$W$ & Weight in cost function \\
\hline$Q$ & Energy exchange rate, $\mathrm{W}$ \\
\hline \multicolumn{2}{|r|}{ State Variables } \\
\hline$\overline{T_{\mathrm{i}}}$ & Indoor air temperature, ${ }^{\circ} \mathrm{C}$ \\
\hline$T_{\mathrm{w}}$ & Wall temperature, ${ }^{\circ} \mathrm{C}$ \\
\hline$T_{\text {soi }}$ & Soil temperature, ${ }^{\circ} \mathrm{C}$ \\
\hline \multicolumn{2}{|r|}{ Subscript } \\
\hline $\mathrm{c}$ & Crops \\
\hline $\mathrm{i}$ & Indoor air \\
\hline o & Outdoor air \\
\hline soi & Soil \\
\hline $\mathrm{r}$ & Energy retrieval \\
\hline $\mathrm{s}$ & Energy storage \\
\hline $\mathrm{v}$ & Ventilation \\
\hline $\mathrm{f}$ & Energy retrieval/storage fan \\
\hline Prd & Predicted with expected weather \\
\hline ws & Wall storage \\
\hline hl & Crop hot loss \\
\hline $\mathrm{cl}$ & Crop cold loss \\
\hline $\mathrm{TL}$ & Crop total loss due to extreme cold \\
\hline SV & The segment-variant set-points \\
\hline SI & The segment-invariant set-points \\
\hline \multicolumn{2}{|r|}{ Control inputs } \\
\hline$\overline{u_{\mathrm{c}}}$ & Control signal for curtain \\
\hline$u_{\mathrm{f}}$ & Control signal of storage/retrieval fan \\
\hline$u_{\mathrm{v}}$ & Control signal of ventilation window \\
\hline \multicolumn{2}{|r|}{ Energy management set-points } \\
\hline$\overline{T_{\mathrm{ir}}}$ & Wall energy retrieval set-point, ${ }^{\circ} \mathrm{C}$ \\
\hline$T_{\text {is }}$ & Wall energy storage set-point, ${ }^{\circ} \mathrm{C}$ \\
\hline$T_{\mathrm{iv}}$ & Ventilation set-point, ${ }^{\circ} \mathrm{C}$ \\
\hline$T_{\mathrm{br}}$ & Best $T_{\text {ir }}$ chosen by energy management \\
\hline$T_{\mathrm{bs}}$ & Best $T_{\text {is }}$ chosen by energy management \\
\hline$T_{\mathrm{bv}}$ & Best $T_{\mathrm{iv}}$ chosen by energy management \\
\hline
\end{tabular}

[References]

[1] Zavala V M, Wang J, Leyffer S, Constantinescu E M, Anitescu M, Conzelmann G. Proactive energy management for next-generation building systems. Fourth National Conference of IBPSA-USA, 2010; 377-385.

[2] Ghoumari M Y E, Tantau H J, Serrano J. Non-linear constrained MPC: Real-time implementation of greenhouse air temperature control. Computers and Electronics in Agriculture, 2005; 49(3): 345-356. 
[3] Gruber J K, Guzmán J L, Rodríguez F. Nonlinear MPC based on a Volterra series model for greenhouse temperature control using natural ventilation. Control Engineering Practice, 2011; 19(4): 354-366.

[4] Dai J F, Luo W H, Li Y X, Qiao X J, Wang C. A microclimate model-based energy consumption prediction system for greenhouse heating. Scientia Agricultura Sinica, 2006; 39(11): 2313-2318

[5] Blasco X, Martínez M, Herrero J M, Ramos C, Sanchis J. Model-based predictive control of greenhouse climate for reducing energy and water consumption. Computers and Electronics in Agriculture, 2007; 55(1): 49-70

[6] Coelho J P, Oliveira P B D M, Cunha J B. Greenhouse air temperature predictive control using the particle swarm optimization algorithm. Computers and Electronics in Agriculture, 2005; 49(3): 330-344.

[7] Körner O, Straten G V. Decision support for dynamic greenhouse climate control strategies. Computers and Electronics in Agriculture, 2008; 60(1): $18-30$.

[8] Sigrimis N, Anastasiou A, Rerras N. Energy saving in greenhouses using temperature integration: a simulation survey. Computers and Electronics in Agriculture, 2000; 26(3): 321-341.

[9] Klein L, Kwak J Y, Kavulya G, Jazizadeh F, Becerik-Gerber B, Varakantham $\mathrm{P}$, et al. Coordinating occupant behavior for building energy and comfort management using multi-agent systems. Automation in Construction, 2012; 22(4): 525-536.

[10] Stluka P, Godbole D, Samad T. Energy management for buildings and microgrids. Decision and Control and European Control Conference (CDC-ECC), 2011 50th IEEE Conference on IEEE, 2011; 413(1): 5150-5157.

[11] Tchamitchian M, Martin-Clouaire R, Lagier J, Jeannequin B, Mercier S. SERRISTE: A daily set point determination software for glasshouse tomato production. Computers and Electronics in Agriculture, 2006; 50(1): 25-47.

[12] Vanthoor B H E, Stigter J D, Henten E J V, Stanghellini C, Visser P H B D, Hemming S. A methodology for model-based greenhouse design: Part 5, greenhouse design optimisation for southern-Spanish and Dutch conditions Biosystems Engineering, 2012; 111(4): 350-368.

[13] Tong G H, Christopher D M, Li T L, Wang T L. Passive solar energy utilization: a review of cross-section building parameter selection for Chinese solar greenhouses. Renewable \& Sustainable Energy Reviews, 2013; 26(10): 540-548

[14] Yang Q, Zhang Y, Fang H, Li W, Lu W, Tong Y. An active heat storage-release system using circulating water to supplement heat in a Chinese solar greenhouse. Acta Horticulturae, 2014; 1037(1037): 49-56.

[15] Zhang M, Li M Z, Wang W Z, Liu C H, Gao H J. Temporal and spatial variability of soil moisture based on WSN. Mathematical and Computer Modeling, 2013; 58(s3-4): 826-833.

[16] Tong G, Christopher D M, Li B. Numerical modeling of temperature variations in a Chinese solar greenhouse. Computers and Electronics in Agriculture, 2009; 68(1): 129-139

[17] Yuan H B, Wang H H, Pang S J, Li L, Sigrimis N. Design and experiment of closed culture system for solar greenhouse. Transactions of the CSAE, 2013; 29(21): 159-165. (in Chinese)

[18] Li L, Li J Y, Wang J H, Sigrimis N A. Thermal modeling and pro-active energy management of solar greenhouses within the IOT environment. International Agricultural Engineering Journal, 2016; 25(1): 94-109.

[19] Sigrimis N, Pasgianos K G A D, Ferentinos K P. Computer Integrated Management and Intelligent Control of Greenhouses. Environment Control in Biology, 2002; 40(1): 39-53.

[20] Sigrimis N, Antsaklis P, Groumpos P P. Advances in Control of Agriculture and the Environment. IEEE Control Systems, 2001; 21(5): $8-12$.

[21] Ferentinos K P, Arvanitis K G, Tantau H J, Sigrimis N. Special aspects of IT for greenhouse cultivation. CIGR Handbook of Agricultural Engineering Volume VI Information Technology, Chapter 5: Precision Agriculture, 2006; pp.294-312.

[22] Laporte G, Asef-Vaziri A. Some applications of the generalized travelling salesman problem. Journal of the Operational Research Society, 1996; 47(12): 1461-1467.

[23] Castelino K, D'Souza R, Wright P K. Toolpath optimization for minimizing airtime during machining. Journal of Manufacturing Systems, 2004; 22(3): 173-180.

[24] Hall N G, Laporte G, Selvarajah E, Sriskandarajah C. Scheduling and lot streaming in flowshops with no-wait in process. Journal of Scheduling, 2003; 6(4): 339-354

[25] Gutin G, Karapetyan D. A memetic algorithm for the generalized traveling salesman problem. Natural Computing, 2010; 9(1): 47-60.

[26] Patel N, Padhiyar N. Modified genetic algorithm using Box Complex method: Application to optimal control problems. Journal of Process Control, 2015; 26: 35-50.

[27] Valls V, Ballestín F, Quintanilla S. A hybrid genetic algorithm for the resource-constrained project scheduling problem. European Journal of Operational Research, 2008; 185(2): 495-508.

[28] Sigrimis N, Rerras N. A linear model for greenhouse control. Transactions of the ASAE, 1996; 39(1): 253-261.

[29] Sigrimis N, Arvanitis K G, Gates R S. A learning technique for general purpose optimizer. Computers and Electronics in Agriculture, 2000; 26(2): 83-103.

[30] Straten G V, Willigenburg L G V, Tap R F. The significance of crop co-states for receding horizon optimal control of greenhouse climate. Control Engineering Practice, 2002; 10(6): 625-632

[31] Li J Y, Li L, Wang H H, Ferentinos K P, Li M Z, Sigrimis N. Proactive energy management of solar greenhouses with risk assessment to enhance smart specialization in China. Biosystems Engineering, 2017; 158: 10-22. 